\title{
Relación entre determinantes socioeconómicos, cobertura en salud y caries dental en veinte países*
}

\section{Relationship between Socioeconomic Determinants, Health Coverage, and Dental Caries in Twenty Countries}

\section{Relação entre determinantes socioeconômicos, cobertura em saúde e a cárie dentária em vinte países}

Fecha de recepción: 06-04-15 Fecha de aceptación: 25-05-15 Disponible en línea: 30-06-15 doi: 10.11144/Javeriana.rgyps18-28.rdsc

Como citar este artículo:

Sanabria-Castellanos CM, Suárez-Robles MA, Estrada-Montoya JH. Relación entre determinantes socioeconómicos, cobertura en salud y caries dental en veinte países. Rev. Gerenc. Polít. Salud. 2015; 14(28): 161-189. http://dx.doi.org/10.11144/Javeriana.rgyps18-28.rdsc

\author{
Cindy Marleyi Sanabria-Castellanos** \\ Moisés Alberto Suárez-Robles*** \\ John Harold Estrada-Montoya****
}

Artículo de investigación. Este documento es uno de los productos de la investigación realizada para optar al título de odontólogo (a) por la Facultad de Odontología de la Universidad Nacional de Colombia. La investigación tuvo el aval del Comité de Ética y Metodología de la Investigación de la Facultad de Odontología de la Universidad Nacional de Colombia. Para su realización no se contó con financiación institucional.

* Odontóloga de la Universidad Nacional de Colombia. Dirección: Carrera 30 No. 45-30, Edificio 210, Ciudad Universitaria, Bogotá D. C., Colombia. Correo electrónico: cmsanabriac@unal.edu.co.

**** Odontólogo de la Universidad Nacional de Colombia. Correo electrónico: masuarezrob@unal.edu.co.

***** Odontólogo, magíster y Ph.D. en Salud Pública de la Universidad Nacional de Colombia. Director del Departamento de Salud Colectiva y profesor titular de la Facultad de Odontología de la Universidad Nacional de Colombia. Bogotá, Colombia. Correo electrónico: jhestradam@unal.edu.co, jhestradam@gmail.com. 


\section{Resumen}

Objetivo: establecer la relación entre determinantes estructurales socioeconómicos, cobertura del sistema de salud y caries dental en veinte países. Métodos: análisis ecológico mixto de datos secundarios de veinte países. Los criterios de inclusión fueron países que presentaran tres valores de COP (cariados, obturados, perdidos) de las últimas cuatro décadas. Las variables independientes fueron: gasto total en salud, gasto sanitario público, índice de pobreza, tasa de alfabetización de adultos, tasa de mortalidad materna, tasa de mortalidad en menores de cinco años y esperanza de vida al nacer. Resultados: la caries dental muestra un valor estable (COP 2,4) desde 1990, con tendencia a disminuir en países más desarrollados y aumentar en los menos desarrollados. Conclusión: los países se clasificaron en tres grupos: universalistas (con mejores los indicadores), dualista y excluyentes (con peores condiciones socioeconómicas). En los países dualistas y excluyentes no se encontró asociación entre prevalencia de caries y factores determinantes socioeconómicos.

Palabras clave: caries dental; salud bucal; sistemas de salud; seguro de salud; países desarrollados; países en desarrollo

\section{Abstract}

Objective: establishing the relationship between structural socioeconomic determinants, coverage of the health system, and dental caries in twenty countries. Methods: ecologic mixed analysis of secondary data of twenty countries. The inclusion criteria were countries that showed three cop values (decayed, filled, lost) during the last four decades. The independent variables were: total expenses on health; public sanitation expenses; poverty index; literacy rate in adults; maternal mortality rate; mortality rate in children younger than 5 and life expectancy at birth. Results: Dental caries shows stable scores (COP 2.4) from 1990, with a tendency toward lower scores in more developed countries and toward higher scores in less developed ones. Conclusion: the countries were classified in three groups: universalist (best indicators), dualist, and excluding (worse socioeconomic conditions). Dualist and excluding countries did now show any association between the prevalence of caries and socioeconomic determinant factors.

Keywords: dental caries; oral health; health systems; health insurance; developed countries; developing countries

\section{Resumo}

Objetivo: estabelecer a relação entre determinantes estruturais socioeconómicas, cobertura do sistema de saúde e cárie dentária em vinte países. Métodos: análise ecológico misto de dados secundários de vinte países. Os critérios de inclusão foram países que apresentaram três valores de COP (cariados, obturados, perdidos) nas últimas quatro décadas. As variáveis independentes foram: despesa total em saúde, despesa sanitária pública, índice de pobreza, taxa de alfabetização de adultos, taxa de mortalidade materna, taxa de mortalidade em menores de cinco anos e expectativa de vida quando nascer. Resultados: a cárie dentária mostra um valor estável (COP 2,4 ) desde 1990, com tendência a diminuir em países mais desenvolvidos e aumentar nos menos desenvolvidos. Conclusão: os países classificaram-se em três grupos: universalistas (com melhores indicadores), dualista e excludentes (com piores condições socioeconómicas). Nos países dualistas e excludentes não foi encontrada associação entre prevalência de cárie e fatores determinantes socioeconómicos.

Palavras-chave: cárie dentária; saúde bucal; sistemas de saúde; seguro de saúde; países desenvolvidos; países em desenvolvimento 


\section{Introducción}

En la actualidad es común encontrar un mayor número de odontólogos que entienden la caries como consecuencia de un proceso multifactorial localizado, el cual puede influir directamente en el bienestar general de la persona. Esta enfermedad, no solo es resultado del proceso bioquímico de transformación de azúcares presentes en la boca, también es reflejo del recorrido que este ser humano ha hecho a lo largo de su vida; por ejemplo, la osteoporosis y la caries dental, enfermedades no trasmisibles, están asociadas directamente a una alimentación poco saludable (1-6).

En los últimos años la palabra prevención ha sido revalorada en la dialéctica salubrista. Se parte de la definición descrita por Winslow en 1920, resumida de la siguiente manera: "la salud pública es la ciencia y el arte de prevenir las enfermedades, prolongar la vida y la promoción de la salud a través de los esfuerzos organizados y decisiones con conocimiento de la sociedad, las organizaciones, públicas y privadas, comunidades e individuos" (7). Por esto, al momento de enfocar el sistema de atención médico-odontológica hacia una orientación basada en la prevención de la enfermedad y la promoción de la salud, se hace necesario tener en cuenta la confluencia de los determinantes. Para comprender el proceso salud-enfermedad de manera global y holística, más allá de lo biológico, se tiene que aceptar una configuración específica de espacio y tiempo históricos, la cual es expresión de procesos vividos en el ambiente del individuo, tales como sus creencias y costumbres, la conformación de su núcleo familiar, alimentación, raza, género, nivel de escolaridad, cambios en la situación económica del sujeto y su familia, barreras geográficas y étnicas entre el enfermo y el servicio sanitario y, por supuesto, el sinnúmero de variantes en las corrientes políticas que ha llevado a la instauración del modelo de salud imperante en su nación.

La comprensión de los sistemas de salud, más allá de su forma organizacional, permite ver el trasfondo político que los explica como respuesta, acertada o no, a la realidad histórica del momento de su creación, a los intereses de los grupos que los fomentaron y a las múltiples variantes ocurridas para que se legislara de esa forma; además, ayuda al profesional de la salud a ver críticamente el momento donde se desarrolla su oficio, su consulta y, por tanto, el devenir profesional, con responsabilidad política activa, así como los deberes encomendados dentro de códigos médicos y éticos vigentes. Son varios los países cuyo enfoque supera los determinantes biológicos y se ubica en una perspectiva del proceso de la determinación social de la salud y la enfermedad.

Los sistemas de salud y las políticas públicas sociales influyen de manera decisiva en el vínculo entre desigualdades sociales y bienestar en salud (5). En muchos casos dichos sistemas fracasan a la hora de satisfacer las necesidades de las poblaciones donde han sido implementados. Es necesario, entonces, entender los sistemas de protección social como parte de las políticas sociales; estos son resultado de una articulación entre los contextos económico, político y social, con la finalidad de explicar su desarrollo a lo largo del tiempo e identificar sus limitaciones y sus alcances (8).

Una vez finalizada la Segunda Guerra Mundial, muchos países optaron por seguir diferentes sistemas de políticas sociales. Diferentes autores han reconocido la dificultad de enmarcar estos sistemas en una clasificación ordinaria, razón por la cual han sugerido diferentes tipologías, aunque sin desconocer las singularidades de cada Estado. Se distinguen tres grandes corrientes 
que identifican la forma como los países han conducido dichas políticas para alcanzar cierto grado de cobertura en sus sistemas de protección social, especialmente en el campo de salud: universalistas, duales y excluyentes. Los llamados universalistas ofrecen acceso a la seguridad social basados en la ciudadanía, llevando a la enseñanza primaria mejoras en infraestructura y servicios básicos de salud a todos o casi todos los conciudadanos (9).

Al lado de estos países, las democracias constitucionales o parlamentarias, altamente participativas aun en la temprana posguerra, presentaban buenos indicadores en salud, así como en salud oral. En los países que siguieron trayectorias políticas más democráticas, universalistas y participativas, cabe destacar el papel protagónico que han tenido las organizaciones de trabajadores, mediante sindicatos y otro tipo de asociaciones, en la creación de estos Estados de bienestar. Estas organizaciones han luchado para que el Estado cumpla sus responsabilidades, presionando por el justo intercambio de fuerza laboral por un pago no solo a nivel salarial, propiamente dicho, sino también que el Estado aumente el gasto en lo social, reconociéndolo como una remuneración económica indirecta a los que producen el avance de las locomotoras que mueven sus finanzas $y$, por consiguiente, que aumente el nivel de vida de estos y sus familias (10).

Dado que no existe suficiente información relevante, adecuada, pertinente, de fácil acceso y asimilación, que de forma confiable y objetiva relacione variables tan globales como los lineamientos económicos coercitivos de entidades supranacionales para comprender los modos estatales de ofrecer la salud, o que midan los resultados en los programas de salud evaluados con diferentes instrumentos, como los índices de sangrado gingival, disminución en el número de dientes de los ciudadanos y otros mecanismos que muestren los logros en salud oral, se hace necesaria una caracterización histórica de las trayectorias políticas de veinte países de diversos continentes y su relación con los sistemas de salud, en aras de entender su funcionamiento y hacer una lectura de la situación general de salud oral en la población en un momento determinado, con base en los datos que se tienen del índice COP (cariados, obturados, perdidos). El objetivo de este artículo es establecer la posible relación entre los determinantes estructurales socioeconómicos, el nivel de cobertura del sistema de salud y la caries dental en veinte países, a partir de información hallada en la literatura internacional.

Organismos internacionales como la Organización Mundial de la Salud (oms), rectora de la salud pública a nivel global, tienen entre sus funciones la recolección y el análisis de diferentes indicadores epidemiológicos, con el fin de hacer un diagnóstico de la condiciones de salud de las poblaciones estudiadas, en este caso el vasto conjunto de países que constituyen el globo terrestre. A finales de la década de los sesenta, esta institución supranacional inició la recolección de datos de salud oral, fijando metas y diseñando distintos sistemas de vigilancia epidemiológica que permitirán, por medio del índice COP, analizar y estudiar el recorrido histórico comportamental de la salud oral en términos de caries dental.

En indicadores COP, tanto de países desarrollados como de países en vía de desarrollo, se siguen leyendo altos niveles de prevalencia de caries. En los países en vía de desarrollo, dichos indicadores llegan en algunos casos a duplicar, e incluso a triplicar, los datos arrojados en los países del Primer Mundo, en donde hay un decrecimiento continuo de estas cifras; por ejemplo, en Guatemala los niños de seis años mostraron un índice de caries en la 
dentición primaria (ceod) de 5,38 dientes cariados, mientras que los niños de Estados Unidos en este mismo grupo de edad tenían un índice de 2,55 (11,12). Los sistemas sanitarios son secuelas históricas que resultan de la configuración específica de la estructura de cada país y son dependientes y subordinados a los procesos básicos con los cuales se cimienta una nación, como lo son los procesos políticos, ideológicos, sociales y culturales (13).

La salud oral no es ajena a esto, motivo por el cual esta investigación tuvo por objetivo establecer la relación entre los determinantes estructurales socioeconómicos, el nivel de cobertura del sistema de salud y la caries dental en veinte países informados en la literatura internacional.

\section{Materiales y métodos}

Se realizó un estudio ecológico mixto, a partir de la recolección de datos secundarios de veinte países y una revisión e interpretación de la literatura internacional y nacional. Este trabajo se llevó a cabo en cuatro etapas, a saber:
1. Revisión bibliográfica, realizada entre julio del 2011 y julio del 2012 en las siguientes bases de datos: Global Health, Medline, OvID, Pubmed, Science Direct, Hinari y Google Scholar, utilizando términos normalizados en MeSH y cruzándolos mediante el uso de operadores boléanos. Adicionalmente, se consultó información referente a los países en los sitios web de la oms, del Banco Mundial, de la Agencia Central de Inteligencia de los Estados Unidos (CIA), de la Organización Mundial del Trabajo (OIT) y de la Comisión Económica para América Latina y el Caribe (Cepal).

2. Tipificación de los países seleccionados. Estos fueron: Suiza, Nueva Zelanda, Vietnam, Estados Unidos, Cuba, Australia, Reino Unido, Dinamarca, Alemania, Brasil, México, Uruguay, Colombia, China, Turquía, República Dominicana, Filipinas, Etiopía, Nigeria y Sudán. Para la clasificación de los veinte países escogidos de acuerdo a la disponibilidad de COP, se seleccionó un grupo de siete indicadores en salud (ver tabla 1), análogos a los escogidos por

Tabla 1. Variables Consideradas PaRa la Clasificación de los Países SEleccionados

\begin{tabular}{|l|l|l|l|}
\hline Variable & Universalista & Dual & Excluyente \\
\hline $\begin{array}{l}\text { Porcentaje del Producto Interno Bruto (PIB) } \\
\text { gastado en salud }\end{array}$ & Mayor a 10\% & Entre 7 y 10\% & Menor de 7\% \\
\hline $\begin{array}{l}\text { Gasto público en salud como porcentaje del gasto } \\
\text { total en salud }\end{array}$ & $75-100 \%$ & $50-75 \%$ & Menor a 50\% \\
\hline $\begin{array}{l}\text { Esperanza de vida al nacer (en años) } \\
\text { Porcentaje de la población que vive bajo la línea } \\
\text { de la pobreza nacional (fuente: cia, diversos años) }\end{array}$ & $0-20 \%$ & $60-75$ & Menor a 60 \\
\hline $\begin{array}{l}\text { Tasa de mortalidad infantil antes del quinto año } \\
\text { de vida x 1000 (2010) }\end{array}$ & $0-6$ & $20-40 \%$ & Más de 40\% \\
\hline $\begin{array}{l}\text { Tasa de mortalidad materna por 100000 neonatos } \\
\text { Porcentaje de población que sabe leer y escribir } \\
\text { (Fuente: cia) }\end{array}$ & $90-100$ & $6-12$ & Mayor a 12 \\
\hline
\end{tabular}


Filgueira, utilizando como criterios de selección la disponibilidad de los datos en todos los países. La asignación de cada país a una de las categorías de cobertura: universalista, dual o excluyente, se hizo cuantificando el número de veces que este aparecía en cada una de las variables-rangos escogidas y se asignaba en aquella que tuviera tres o más veces.

3. Análisis e interpretación de la información obtenida en la revisión bibliográfica.

4. Caracterización de las trayectorias políticas de los países seleccionados. Análisis e interpretación de la información obtenida.

Limitaciones: por ser este un estudio interpretativo de tipo ecológico, la recolección de los datos proviene de diferentes fuentes secundarias, las cuales, aun cuando fidedignas pueden tener deficiencias en la calidad de recolección, pues al realizarse la prueba a fin de determinar COP intervienen diversos factores que pueden alterar el valor real del índice, como puede ser el caso de que una fisura dental pigmentada y/o profunda se confunda con caries, o que una anodoncia sea registrada como diente perdido, por sesgo de memoria del entrevistado. Los datos presentados de COP en los diferentes países por décadas deben ser leídos dentro de estas limitaciones y entendidos como una herramienta que aproxima a la comprensión de la condición de salud oral de la población evaluada y no como un valor nominal, frío y estático. De igual manera, para todas las interpretaciones referentes al valor de COP mundial presentado en este estudio, se parte de la premisa de que se está ante un valor de referencia global originado por la aproximación estadística realizada por Poul Erik Petersen para la oms, en la cual se intenta promediar los valores reportados, tanto por los países desarrollados como por aquellos en vía de desarrollo. Por lo tanto, no debe asumirse como un valor neto de la caries en cada región del mundo.

\section{Resultados}

\section{Caries dental}

La caries dental es una de las enfermedades crónicas multifactoriales más prevalentes a nivel global, afecta lenta y progresivamente a la población mundial (14-18), las más de las veces niños y niñas entre los tres, cinco, seis y doce años de edad (2,19-21). Es uno de los principales problemas de salud pública y de mayor peso en la historia de morbilidad bucal, junto con la enfermedad periodontal $(15,22,23)$. El signo clínico característico de la caries en sus etapas más avanzadas es la destrucción del diente, como consecuencia de la desmineralización generada por la fermentación provocada por los ácidos producidos por la placa bacteriana. Estos ácidos son productos finales del metabolismo ácido de las bacterias y son capaces de fermentar los carbohidratos ingeridos en la dieta alimenticia, generan una destrucción química dental en tejidos duros como el esmalte, la dentina y el cemento radicular $(14,16,22,24,25)$.

El desarrollo de la lesión cariosa requiere que el biofilm dental sea mantenido sobre la superficie dental por un largo periodo (14), es decir, la lesión cavitaria se dará cuando existan estadios avanzados. Las lesiones cariosas del esmalte se observan en distintos estadios, primero como una pequeña mancha blanca, con pequeñas áreas de desmineralización, luego como una mancha pigmentada o una irregularidad de la superficie dental al examen clínico, finalizando en la lesión avanzada en forma de cavidad $(26,27)$.

Las primeras etapas de la lesión cariosa no se detectan con un examen clínico tradicional 
ni con un examen radiográfico; sin embargo, al interrumpirse el equilibrio microbiológico del biofilm, se detiene el proceso de destrucción de la superficie dental, por ello el principal tratamiento en estos estadios consiste en medidas medianamente invasivas como la exposición a flúor tópico, colocación de sellantes, pulido coronal, acompañado de mejoramientos en las condiciones, técnicas y conocimientos del cuidado personal y hábitos en higiene oral que influyan en el comportamiento del individuo, terapias conocidas como promoción de la salud y prevención de la enfermedad (16,28-30).

Como en toda enfermedad, entre los determinantes de la caries dental comúnmente identificados están los macroestructurales, tales como los económicos, políticos y socioculturales, que influyen en el recorrido sociohistórico del individuo, así como el nivel de educación tanto poblacional como individual, los ingresos económicos y el estrato socioeconómico, la condición laboral, la relación socioambiental con su entorno, el género, la edad, la condición sistémica del individuo, la higiene bucal, algunos medicamentos, el ph salivar, la dieta alta en azúcares y demás factores relacionados directa e indirectamente con el individuo $(31,32)$.

En el proceso de la caries dental intervienen factores biológicos promotores de su aparición: la proliferación de microrganismos con potencial cariogénico en el ecosistema bucal que requieren patrones dietéticos específicos, los defectos del esmalte, el $\mathrm{pH}$, la viscosidad y el flujo salivar, las características anatómicas del diente, la relación dental, la condición sistémica y la condición nutricional, la edad, el sexo y la raza, entre otros.

Existen también los llamados factores sociales, que hacen referencia a los determinantes supraestructurales de contenido político, económico y cultural, como son la educación del individuo, los hábitos en el cuidado y la higiene oral, la capacidad de adquisición de los elementos necesarios para la práctica de dichos cuidados, el acceso a los servicios de salud en cuanto a promoción de la salud, prevención y tratamiento de la enfermedad (33-37).

En la prevalencia a nivel mundial se refleja que, si bien existe una disminución del cop global, la incidencia de caries sigue siendo elevada en la mayoría de países latinoamericanos y algunos africanos, puesto que aun cuando se identifican las formas de prevenirla, no existen recursos o políticas de salud que propendan por la erradicación. Por otra parte, países europeos, asiáticos y potencias como Estados Unidos reducen considerablemente la prevalencia de caries dental, como resultado de políticas nacionales de salud cobijadas bajo sistemas nacionales de salud que, no solo brindan acciones colectivas como fluorización de sal y agua, sino que además permiten el acceso a programas preventivos y curativos oportunos de carácter individual, basados en la ciudadanía o en relaciones contractuales estables (38-40).

A lo largo del tiempo se han desarrollado diferentes criterios de evaluación, con el fin de identificar la presencia de la caries dental, entre ellos el tradicional, basado en el uso del explorador; sin embargo, los estadios de enfermedades crónicas como la caries dental comúnmente son caracterizados de acuerdo con la severidad de la dolencia.

Entre los métodos utilizados se encuentran: un método de evaluación visual, encarnado en el Sistema Internacional de Detección y Valoración de Caries (ICDAs [International Caries Detection and Asessment System]); el Índice Significativo de Caries Dental (SIC [Significant Caries Index]); el Índice COP (dientes cariados, obturados y/o perdidos 
[DMFT, por las siglas en inglés Index: decayed, missing and filled teeth]).

Como se mencionó en los aspectos metodológicos y como se verá más adelante, el COP es un índice descriptivo de complejidad baja, que pretende hacer un acercamiento a las condiciones de salud oral en una comunidad o individuo, con una relevancia mayor a la de solo su valor nominal numérico, por lo que se decidió usarlo como referente para la realización de este estudio, pese a que las medidas reportadas por los autores originales pueden no corresponder a una verdad absoluta en cuanto a caries de su población, así como los criterios de cada evaluador pueden estar o no correctamente calibrados $(25,26,41-44)$.

El análisis e interpretación del índice COP se debe descomponer en cada una de sus partes como cariados, obturados y perdidos, expresándolo en porcentajes o promedios. El índice COP debe ser medido en las poblaciones a distintas edades durante el desarrollo de la vida. La OMs propone como edades para hacer el estudio epidemiológico los 5-6 años, 12, 15, 18 años, 35-44 años y 60-74 años de edad de los individuos y solo considera 28 dientes.

Para realizar la comparación del estado de salud bucal de los países, la oms recomienda medir el cor a los doce años de edad, ya que esta edad es aquella en la que han terminado de hacer erupción todos los dientes permanentes y se evidencian las políticas de prevención y promoción que tenga cada país en su sistema de salud. Según la oms, en 1969 se da el primer reporte de COP de carácter mundial. En este se encuentra una tipología sustantiva de representación del índice COP, nominando como muy bajo los rangos de 0,0 a 1,1 ; bajo de 1,2 a 2,6; intermedio de 2,7 a 4,4; alto de 4,5 a 6,5; y muy alto mayor a 6,5. A nivel mundial se pueden dividir o agrupar países de acuerdo con el resultado en el Índice COP que se obtuvo en niños de doce años de edad, así (45-49):

- $\quad$ COP muy bajo < 1,2: China, Argelia, Libia y Sudáfrica, entre otros.

- COP bajo de 1,2 a 2,6: Nigeria, Egipto, Siria, Irán, Irak e India, entre otros.

- COP intermedio de 2,7 a 4,4: Alaska, Perú, Venezuela, Ecuador, Chile, España, Italia, Rusia, Paraguay y Uruguay, entre otros.

- $\quad$ COP alto de 4,5 a 6,5: Gran Bretaña.

- COP muy alto > 6,5: Argentina, Canadá, Noruega y Finlandia, entre otros.

Más tarde, en un reporte de la oms en el 2003, se nomina el rango de COP muy bajo cuando es menor a 1,2 , bajo de 1,2 a 2,6, moderado de 2,7 a 4,4, elevado cuando es mayor a 4,4. En este reporte Dinamarca se posiciona con uno de los índices más bajos, Bolivia con el más alto y Brasil con un índice moderado, lo cual demuestra el cambio operado en salud oral debido a las políticas públicas que marcan las trayectorias políticas y económicas adoptadas en los distintos países.

Hoy en día el índice COP se encuentra institucionalizado como una herramienta cuantificable de morbilidad bucal en las poblaciones, es utilizado por organismos internacionales y nacionales que buscan promover el estudio de las incidencias y prevalencias de enfermedades orales, lo cual fortalece el hecho de que los cambios en las condiciones estructurales de un Estado influyen directamente en el nivel de salud oral de la población (47,50-54).

Países como Finlandia y Noruega, caracterizados por tener un alto nivel de vida, muestran también uno de los mejores 
comportamientos a nivel de salud oral en el mundo y disponen de valores que han evolucionado a través del tiempo y han permitido un descenso en el valor de cop de sus respectivas poblaciones. Ejemplo claro de ello es el Informe Nórdico sobre Salud Oral, de acuerdo con el cual Finlandia en 1975 tenía un cop de 6,9 y pasó en el 2000 a un índice de 1,2, en tanto que Noruega pasó de 3,4 en 1985 a 1,6 en el 2006 en niños de doce años (51).

En África y Asia hay estudios de morbilidad bucal que permiten deslumbrar superficialmente el nivel de salud oral que se encuentra en el mundo. Así consta en el reporte de la OMS "Mejora de la salud oral en África en el siglo xxI", el cual hace referencia a un aumento en la severidad de caries dental en países europeos y americanos, según los criterios de la OMs. En el 2000 el promedio mundial del índice cop es de 2,4, aproximadamente, lo cual refleja un cambio en el consumo de azúcares e intervenciones como la fluorización $(53,54)$.

En Colombia el cop en niños de doce años de edad, según el Ensab III, para la variable sexo es: en hombres 2,1 y en mujeres 2,5; según la zona: urbana 2,3 y rural 2,3; en subregiones como San Andrés el valor es de 1,6; Barranquilla: 1,8; Orinoquía y Amazonía: 3,3; andén Pacífico: 2,3; Cali: 1,7; Medellín: 1,8 y Bogotá: 3,1 (52).

Estos resultados constituyen un acercamiento a lo que realmente se cuestiona cuando se observan cifras decimales de una herramienta cuantificable de enfermedad de salud oral, como lo es el COP (44); asimismo, ejemplifican el producto de diversas interacciones que tienen un trasfondo económico, político, social y cultural, pero que se encuentran ocultas y no son visibles para el lector desprevenido, incluidos los odontólogos en formación.
Las alternativas escogidas para realizar estudios de cuantificación de niveles de salud oral en el mundo y en nuestro país, no son lo que realmente inquieta, ya que no son más que cifras vagas, si no las relacionamos con la realidad que aqueja de manera desigual a los países en un mundo globalizado. Así, se limita la razón de los resultados, si no se toma y se comprende lo que circunscribe y determina nuestra sociedad, como la política, la economía, la historia y cultura de cada pueblo, en últimas, la razón de esperar, vivir y morir.

Los factores y procesos que influyen en que exista o no cierto tipo de resultado en COP son cada una de las cosas que vemos cuando nos levantamos; cuando nos alimentamos; cuando salimos de la casa; cuando llegamos a nuestras escuelas, universidades o institutos; cuando llegamos a nuestro trabajo, si es que hay; cuando entablamos relaciones interpersonales; cuando accedemos a nuestros servicios de salud; cuando observamos la política "democrática" de nuestro país, en fin, cuando sabemos que todo lo que hay alrededor nuestro influye en el sujeto (individuo-pueblo) y este se convierte en muestra fidedigna de cada proceso, como consecuencia de todo lo anterior.

\section{Objetivos de Desarrollo del Milenio y objetivos globales para la salud bucodental}

Los Objetivos de Desarrollo del Milenio (ODM), también conocidos como Objetivos del Milenio, fueron propuestos por las $\mathrm{Na}$ ciones Unidas en el año 2000, en Nueva York, del 6 al 8 de septiembre. Surgieron a raíz del desaprovechamiento y la pérdida de utilidad de la Ayuda Oficial de Desarrollo (AOD) de 1990, luego de la caída del muro de Berlín, 
cuando los países la tomaron como una herramienta contra el terrorismo.

La Cumbre del Milenio celebrada en ese entonces reunió aproximadamente a 189 países miembros de las Naciones Unidas, con el fin de firmar la Declaración del Milenio, cuyo objetivo era definir la formación de bases sólidas de un mundo más pacífico, próspero, más justo, y por ende reducir la pobreza, el hambre, la desigualdad de género, la carencia de educación, la falta de acceso al agua potable y la degradación del medio ambiente, así como promover la salud a nivel mundial. En la actualidad 1200 millones de personas subsisten con un dólar al día, otros 925 millones sufren de hambre, 114 millones de niños no acuden a la escuela y once millones de menores de cinco años pierden la vida, sin contar con que el SIDA mata en promedio a tres millones de personas por año y que 2400 millones de personas no tienen acceso a agua potable $(53,54)$.

Los objetivos globales para la salud bucodental fueron establecidos por la Federación Dental Internacional (FDI) y la oms en 1981 y estaba estipulado que se cumplieran en el año 2000 (54). Fueron evaluados al final de dicho periodo y se llegó a la conclusión de que algunas poblaciones los alcanzaron y muchas otras no lo hicieron. Posteriormente, la oms llevó a cabo una evaluación del logro de los objetivos e inició la formulación de unos objetivos para el año 2020, luego de examinar, por medio del Taller de Trabajo de la Sección de Salud Pública de la FDI en octubre de 1999, aquellos objetivos de la Ciudad de México de 1981.

Algunos miembros de la FDI, la oms y la International Association for Dental Research (IADR), escogidos de distintas partes del mundo, formaron un grupo que se encargó

170 de preparar nuevos objetivos para el 2020, los cuales fueron sometidos a evaluación y consideración de centros de colaboración en salud oral de la oms, asociaciones dentales nacionales y otros grupos interesados en el tema. Para el año 2020 las metas, objetivos y blancos globales para la salud oral se circunscriben a promover la salud bucodental y minimizar el impacto de la enfermedades de origen bucodental y cráneo-facial, teniendo en cuenta su impacto en la salud física general, así como el impacto psicosocial, tomando como blanco aquellas poblaciones más afectadas, además de minimizar el impacto de las manifestaciones cráneo-faciales y orales de las enfermedades, usándolas como un método para el diagnóstico precoz, la prevención y el manejo de enfermedades sistémicas asociadas.

Entre los objetivos globales para la salud bucodental que aparecen en un informe del 2003 se encuentran:

- Disminuir la mortalidad por enfermedades bucodentales y cráneo-faciales.

- Reducir la morbilidad de las enfermedades bucodentales y cráneo-faciales, con el fin de mejorar la calidad de vida.

- Promover políticas y programas sostenibles en los sistemas de salud oral, de acuerdo con las prioridades; es decir, aquellas que se encuentren sustentadas con evidencia científica.

- Desarrollar sistemas de salud oral para la prevención y el control de enfermedades bucodentales y cráneo-faciales, que tengan como característica ser accesibles y costo-eficaces, usando como método predictor el factor de riesgo en común.

- Formar un conjunto entre promoción y atención en salud oral. 
- Desarrollar programas de salud oral con el fin de mejorar la salud en general.

- Fortalecer los sistemas y métodos de vigilancia en salud oral, tanto en su resultado como en el proceso.

- Promover la ética y la responsabilidad social entre los encargados de la atención.

- Disminuir las disparidades y desigualdades en salud oral entre los distintos grupos socioeconómicos de cada país.

- Aumentar la vigilancia epidemiológica de las enfermedades y de los trastornos orales.

\section{Contexto político-económico mundial del surgimiento de los sistemas de seguridad}

Los sistemas de seguridad social son estructuras complejas, de naturaleza heterogénea, que se han desarrollado a lo largo de la historia con un sinnúmero de características particulares, de acuerdo con el país en donde han sido implementados. Dichas estructuras responden de manera acertada o no a las condiciones socioeconómicas y a las necesidades propias de un pueblo, pero siempre en el contexto de un amplio panorama histórico, económico y político, cambiante, dinámico, que da razón del porqué de su surgimiento. Por esta razón, se hace indispensable a la hora de estudiar dichos sistemas, un recuento general de los principales acontecimientos a nivel global que motivaron el surgimiento de dichas políticas, sin duda enmarcadas en las constantes luchas sociales que ha despertado el capitalismo, el cual hoy en día se impone como principal rector de dichos procesos; por ello su estudio se vuelve obligatorio (13,55-62).
La seguridad social a cargo del Estado surgió con la implantación del capitalismo, el cual rompió las redes de apoyo construidas antes de su puesta en escena, principalmente la familia y la relación de los trabajadores con el señor feudal. Tales sistemas están envueltos en las diferentes relaciones económicas y políticas que asumen sus actores, el Estado, con sus connotaciones internacionales pertinentes, el ciudadano, con su capacidad de aportar mediante su fuerza de trabajo al Estado, y por supuesto el capital, como regente invisible (no tanto) de dichas relaciones.

En este sentido, es importante mencionar que en este trabajo se usa el término seguridad social para designar ese pago social (entendido por pago social un gasto social que desde el Estado busca retribuir beneficios para la sociedad), concepto que ha tenido múltiples variantes, como en el caso europeo, en el cual se conoció dicho fenómeno como Estado de Bienestar o Welfare State, mientras que dadas las condiciones particulares de Latinoamérica, este tomó otros nombres y formas bajo la figura de medicina estatal. Diferentes autores a lo largo de las décadas han intentado dar una definición a este fenómeno, en el cual el Estado reconoce la pobreza como un problema social (63-71).

El Welfare State tiene su origen en el proceso de industrialización, el cual permitió un aumento poblacional con migración de los habitantes del campo a la ciudad, lo que conllevaría un rompimiento de las redes tradicionales de solidaridad e integración, ya que se empezaron a imponer grandes unidades productivas que necesitaban para su funcionamiento grupos relativamente homogéneos de trabajadores, los cuales empezaron a cuestionar su función y a generar movilización y organización, dando forma a lo que se conocería como la nueva clase trabajadora. Esta nueva clase obrera para ser representativa ante el Estado se vio obligada a fomentar la evolución de la democracia 
Tabla 2. Propuestas clasificatorias para eValuar sistemas de Seguridad social

\begin{tabular}{|c|c|c|c|c|}
\hline $\begin{array}{c}\text { Mesa Lago: 1978, } \\
\text { año de imposición } \\
\text { del sistema }\end{array}$ & $\begin{array}{c}\text { Esping Andersen: } \\
\text { 1995, corriente } \\
\text { política }\end{array}$ & $\begin{array}{c}\text { Filgueira: } \\
\mathbf{1 9 9 7 ,} \\
\text { cobertura }\end{array}$ & $\begin{array}{c}\text { Fleury: 1997, carácter } \\
\text { de ciudadano }\end{array}$ & Cepal: 1998 \\
\hline Pioneros & $\begin{array}{c}\text { Estado providencia } \\
\text { liberal }\end{array}$ & $\begin{array}{c}\text { Universalismo } \\
\text { estratificado }\end{array}$ & Asistencialista/residual & Gasto alto \\
\hline Intermedios & $\begin{array}{c}\text { Estado providencia } \\
\text { conservador }\end{array}$ & Duales & $\begin{array}{c}\text { Seguridad } \\
\text { social/meritocrático }\end{array}$ & Gasto medio \\
\hline Tardíos & $\begin{array}{c}\text { Estado providencia } \\
\text { social demócrata }\end{array}$ & Excluyentes & Seguridad/institucional & Gasto bajo \\
\hline
\end{tabular}

Fuente elaboración propia

de masas, con la creación y surgimiento de partidos obreros, los cuales en la mayoría de los casos mostraban comportamientos propios de políticas socialistas, democratizadoras, con el reconocimiento de la ciudadanía como herramienta de validación del sujeto ante el Estado (70).

La simbiosis Estado-ciudadano trajo consigo un aumento de la productividad del trabajo y de la riqueza acumulada que permitió el surgimiento de un bloque burocrático estatal. Este, por medio del dominio de las técnicas administrativas, impulsó un aumento de la intervención por parte del Estado. Dicho aumento, a su vez, ayudó al nacimiento y fomento de métodos redistributivos que propenden por encontrar una salida política a las luchas de clases (71).

En síntesis, los sistemas de seguridad social surgen de la articulación de tres procesos, dependientes el uno del otro: un proceso económico, como lo fue la mercantilización de la fuerza de trabajo y la industrialización; un proceso social, con el nacimiento de nuevas clases sociales; $y$ un proceso político, de luchas sociales que buscaban legitimización. Por lo tanto, se entiende que si bien distintos autores han hecho esfuerzos por hacer una

172 clasificación teórica de los sistemas para que se enmarquen en un equipo de modelo ideal, con cada característica que se busca usar para sopesar un modelo con otro, cada país genera una situación propia, lo cual dificulta la creación de una clasificación definitiva de dichos sistemas por parte de los autores. La tabla 2 relaciona las propuestas clasificatorias de algunos autores con los niveles, año de postulación y la variable que se evalúa (65-70).

Este trabajo tomó como referente la clasificación elaborada por Filgueira, quien con base en los trabajos de Esping-Andersen propone caracterizar a los modelos de política social añadiendo las variables no solo de cuánto se gasta, sino cómo se gasta y la capacidad del gasto en redistribuir las brechas entre los grupos sociales (70).

\section{Universalistas}

Universalismo estratificado, principalmente en países como Uruguay, Argentina y Chile, en donde los servicios llegan a casi toda la población, pero de una forma estratificada. Si bien estos países latinoamericanos transitaban por duras dictaduras militares o civiles, tendencias innovadoras como la de sustitución de importaciones permitieron el ingreso de mano de obra nacional y extranjera al mercado interno, lo que produjo sindicalización de la mayoría obrera y presión por parte de movimientos políticos y sociales. 
Este tipo de Estado social se caracteriza por brindar protección, de una u otra forma, al grueso de la población, mediante sistemas de seguro social, de servicio de salud, al mismo tiempo que llevan educación primaria y básica secundaria a toda la población, mientras permiten una fuerte estratificación en los paquetes de beneficios a los que se puede acceder, así como las dinámicas necesarias para llegar a ellos. Se reconoce una estratificación en calidad y acceso, pero en últimas un mínimo de beneficios que recuerdan a los Estados de Bienestar europeos $(9,64)$.

Esta clasificación quedaría incompleta si no se entiende que no por el hecho de que países como China, Vietnam o Cuba hayan decidido un tránsito político y económico totalmente diferente al del resto de los países, con una clara influencia de la Unión Soviética y en contravía del modelo capitalista hegemónico en la mayoría del mundo, deban ser excluidos de la clasificación, sino que por el contrario debería abrirse una nueva categoría llamada países universalistas, estatistas o absolutistas, cuyos casos son los más parecidos al Estado de Bienestar europeo, pero que surgieron en una realidad diferente dada su inclinación socialista.

\section{Dualistas}

En los dos gigantes latinoamericanos, México y Brasil, las milagrosas recuperaciones económicas han sido evidentes; en ello primó la existencia de regímenes duales, en los cuales predominan las formas clientelistas y patrimonialistas de incorporación a los sistemas de protección, mientras que en República Dominicana, Guatemala, Honduras, El Salvador, Nicaragua, Bolivia y Ecuador, regímenes excluyentes, fueron muy pocos los beneficiados del gasto social.

Estos regímenes, en la década de los setenta presentaban un casi universalizado desarro- llo de la educación básica inicial, así como un importante aunque estratificado grado de cobertura en el sector salud, lo que repercutía en la seguridad social, pues la cobertura que brindaba acentuaba los aspectos estratificados de los sistemas maduros, sin llegar a la cobertura universalizada de los regímenes de universalismo estratificado. Todo esto sumado a la ya preocupante heterogeneidad territorial en los aspectos referentes al desarrollo económico y social, evidenciando y reproduciendo una estructura con un alto contenido federalista $(9,13,67)$.

\section{Excluyentes}

Con la excepción de Costa Rica, la mayoría de países centroamericanos y posiblemente Bolivia y Ecuador, al igual que los países más pobres del continente africano, presentan sistemas elitistas de seguro social y salud y duales en materia de educación. Esto no sorprende, habida cuenta que la pobreza calculada en todos estos países, a través de ingresos, excede el escandaloso $50 \%$, y menos del $20 \%$ de la población se encuentra cubierta por programas básicos de protección y seguridad social (70).

En 1992 Peter Evans denominó a este tipo de naciones como de Estados depredadores, en los cuales las élites minoritarias logran dar captura al poder del aparato estatal, implementando la exportación salvaje de bienes primarios, en economías precarias que utilizan la capacidad fiscal de estos Estados para extraer dividendos, sin proveer la contraparte de bienes colectivos (pago social), sea ello en la forma de infraestructura, regulación o servicios sociales que propendan por un estrechamiento de las brechas de desigualdad e iniquidad (71).

Antes de destacar los indicadores y los rangos descriptivos que se seleccionaron para la clasificación de los países que conforman 
el grupo de este estudio, conviene señalar algunos conceptos básicos de lo que son dichos indicadores.

Los indicadores en salud son variables que intentan medir objetivamente, en forma cualitativa o cuantitativa, sucesos colectivos para poder respaldar acciones políticas, hacer comparación de logros y materialización de resultados que midan los objetivos alcanzados, dando una idea general de cómo está la situación que se pretende evaluar. Dada dicha función, se requiere el cumplimiento de características especiales como buena disponibilidad, simplicidad, validez, especificidad, confiabilidad, sensibilidad y alcance. En palabras de la Organización Panamericana de la Salud (OPS), un indicador en salud es "una noción de la vigilancia en salud pública que define una medida de la salud (la ocurrencia de una enfermedad o de otro evento relacionado con la salud) o de un factor asociado con la salud (el estado de salud u otro factor de riesgo) en una población especificada" (72).

En términos generales, los indicadores de salud son representaciones de medidas que, a manera de resumen, logran dar con información pertinente y relevante sobre variados atributos y dimensiones del estado de salud, en especial del desempeño del sistema de salud vigente, y que analizados en conjunto logran reflejar la situación sanitaria de una población, permitiendo hacer vigilancia sobre ella. Por ejemplo, la tasa de mortalidad infantil no es simplemente un número de defunciones de menores, sino que es un indicador del estado de salud de la población, dado que son múltiples las variables que determinan este suceso (desnutrición, inmunización, acceso a agua potable, entre otros), por lo que dicha cifra es sensible también para evaluar el bienestar global de una población.

\section{Tipificación de los países}

Para la clasificación de los veinte países escogidos fue seleccionado un grupo de siete indicadores en salud, análogos a los escogidos por Filgueira. Sin embargo, el autor propone algunos indicadores que no se encuentran disponibles fácilmente para todos los países, por lo cual se incluyen indicadores nuevos que enriquecen la caracterización de la cobertura en salud, utilizando como criterios de selección la disponibilidad de los datos en todos los países, como por ejemplo mortalidad materna y mortalidad para menores de cinco años, así como su origen desde una fuente confiable de fácil acceso (ver tabla 3). En la columna izquierda se encuentra la variable (indicador) objeto de estudio. Las otras tres columnas adicionales, cada una encabezada por los rangos escogidos de acuerdo con los valores propuestos por los diferentes autores revisados en la literatura, pretenden caracterizar en tres subgrupos la cobertura en salud. Los resultados del índice COP se presentan en las figuras 1, 2 y 3, según la tipificación construida de los países seleccionados.

\section{Discusión}

La asignación de cada país a una de las categorías de cobertura (universalista, dual o excluyente) se hizo cuantificando las veces que aparecía el país en cada una de las variables-rangos escogidas y se asignaba en la que apareciera tres o más veces. Por ejemplo: Alemania, Nueva Zelanda y Dinamarca aparecen las siete veces en el rango de universalistas y por ello se asignaron a este subgrupo. En casos límite como el de China, México y Turquía, que tenían tres valores en dos de los rangos, se optó por asignarlos según la caracterización cualitativa de su sistema de salud, es decir, a mayor robustez y compromiso del Estado con el sector salud, esto los inclinaría por universalistas, y, 
Tabla 3. Tipificación de Países en universalistas, duales y eXCluyentes

\begin{tabular}{|c|c|c|c|}
\hline $\begin{array}{l}\text { Indicador/grado de } \\
\text { cobertura }\end{array}$ & Universalistas & Duales & Excluyentes \\
\hline & Mayor a $10 \%$ & Entre 7 y $10 \%$ & Menor a $7 \%$ \\
\hline $\begin{array}{l}\text { Porcentaje de PIB } \\
\text { gastado en salud }\end{array}$ & $\begin{array}{c}\text { Nueva Zelanda, Cuba, } \\
\text { Dinamarca, Suiza, Alemania, } \\
\text { Estados Unidos }\end{array}$ & $\begin{array}{l}\text { Colombia, Uruguay, } \\
\text { Australia, Brasil, Reino } \\
\text { Unido }\end{array}$ & $\begin{array}{l}\text { Filipinas, Etiopia, China, } \\
\text { Nigeria, República } \\
\text { Dominicana, Turquía, } \\
\text { Vietnam, Sudán, México }\end{array}$ \\
\hline \multirow{2}{*}{$\begin{array}{l}\text { Gasto público } \\
\text { en salud } \\
\text { como porcentaje de } \\
\text { gasto total en salud }\end{array}$} & $75-100 \%$ & $50-75 \%$ & Menor a $50 \%$ \\
\hline & $\begin{array}{c}\text { Cuba, Dinamarca, Reino } \\
\text { Unido, Nueva Zelanda, } \\
\text { Alemania, Turquía }\end{array}$ & $\begin{array}{l}\text { Colombia, Australia, } \\
\text { Uruguay, Suiza, China, } \\
\text { Etiopia, Estados Unidos }\end{array}$ & $\begin{array}{c}\text { México, Brasil, República } \\
\text { Dominicana, Nigeria, } \\
\text { Vietnam, Sudán, Filipinas }\end{array}$ \\
\hline \multirow[b]{2}{*}{$\begin{array}{l}\text { Esperanza de vida al } \\
\text { nacer en años }\end{array}$} & 75 o más & $60-75$ & Menor 60 \\
\hline & $\begin{array}{c}\text { Australia, Suiza, Nueva } \\
\text { Zelanda, Alemania, Reino } \\
\text { Unido, Cuba, Dinamarca, } \\
\text { Estados Unidos, México, } \\
\text { Uruguay, Vietnam }\end{array}$ & $\begin{array}{c}\text { Turquía, China, Colombia, } \\
\text { Brasil, República } \\
\text { Dominicana, Filipinas, } \\
\text { Sudán }\end{array}$ & Etiopía, Nigeria \\
\hline \multirow[b]{2}{*}{$\begin{array}{l}\text { Porcentaje de la } \\
\text { población que vive } \\
\text { bajo línea de la } \\
\text { pobreza nacional } \\
\text { (fuente: CIA, diversos } \\
\text { años) }\end{array}$} & $0-20 \%$ & $20-40 \%$ & Más de $40 \%$ \\
\hline & $\begin{array}{c}\text { Australia, Nueva Zelanda, } \\
\text { Cuba, Dinamarca, Suiza, China, } \\
\text { Uruguay, Alemania, Estados } \\
\text { Unidos, Reino Unido, Vietnam, } \\
\text { Turquía }\end{array}$ & $\begin{array}{l}\text { Filipinas, Brasil, México, } \\
\text { Colombia, Etiopia, Sudán }\end{array}$ & $\begin{array}{c}\text { República Dominicana, } \\
\text { Nigeria }\end{array}$ \\
\hline \multirow[b]{2}{*}{$\begin{array}{l}\text { Tasa de mortalidad } \\
\text { infantil antes del 5o } \\
\text { año de vida x } 1000\end{array}$} & $0-6$ & $6-12$ & Mayor 12 \\
\hline & $\begin{array}{c}\text { Alemania, Dinamarca, } \\
\text { Australia, Suiza, Reino Unido, } \\
\text { Nueva Zelanda, Cuba }\end{array}$ & Estados Unidos, Uruguay & $\begin{array}{l}\text { México, Turquía, China, } \\
\text { Brasil, Colombia, República } \\
\text { Dominicana, Filipinas, } \\
\text { Vietnam, Sudán, Etiopía, } \\
\text { Nigeria }\end{array}$ \\
\hline \multirow[b]{2}{*}{$\begin{array}{l}\text { Tasa de mortalidad } \\
\text { materna por } 100000 \\
\text { mil neonatos }\end{array}$} & 20 o menos & $21-100$ & Más de 100 \\
\hline & $\begin{array}{l}\text { Alemania, Australia, Suiza, } \\
\text { Dinamarca, Reino Unido, } \\
\text { Nueva Zelanda, Turquía }\end{array}$ & $\begin{array}{l}\text { Estados Unidos, Uruguay, } \\
\text { China, México, Brasil, } \\
\text { Vietnam, Cuba, Colombia, } \\
\text { Filipinas }\end{array}$ & $\begin{array}{l}\text { República Dominicana, } \\
\text { Etiopía, Nigeria, Sudán }\end{array}$ \\
\hline \multirow[b]{2}{*}{$\begin{array}{l}\text { Porcentaje de } \\
\text { población que } \\
\text { sabe leer y escribir } \\
\text { (fuente: CIA) }\end{array}$} & $90-100$ & $80-90$ & Menos de 80 \\
\hline & $\begin{array}{c}\text { Cuba, Australia, Nueva } \\
\text { Zelanda, Dinamarca, Suiza, } \\
\text { Alemania, Estados Unidos, } \\
\text { Reino Unido, Uruguay, } \\
\text { Vietnam, Filipinas, China, } \\
\text { Colombia }\end{array}$ & $\begin{array}{c}\text { Brasil, Turquía, República } \\
\text { Dominicana, México }\end{array}$ & Nigeria, Sudán, Etiopía \\
\hline
\end{tabular}

Fuente: elaboración propia 


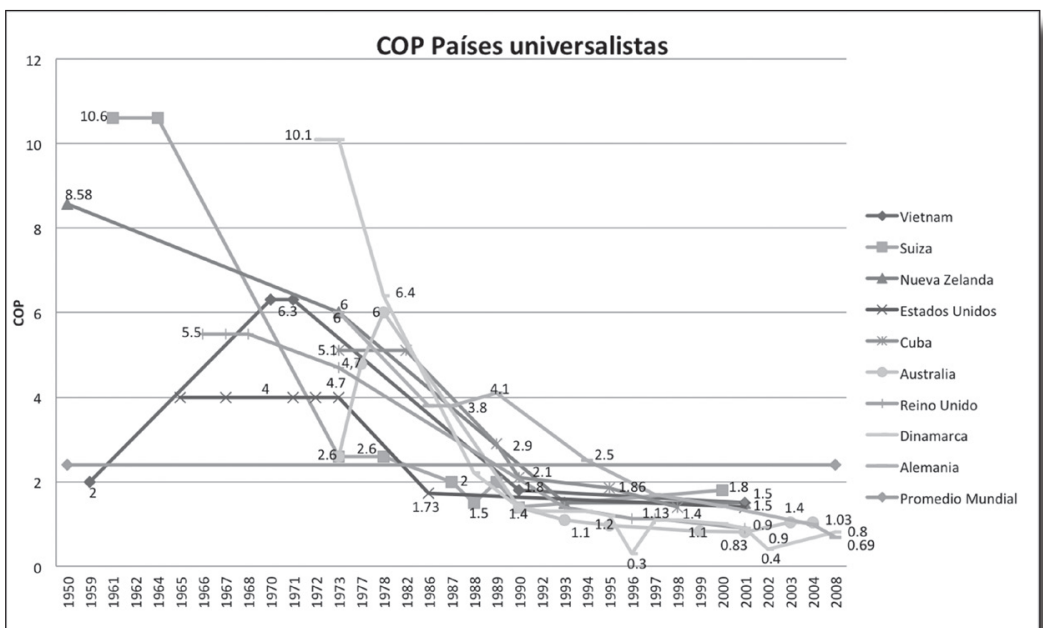

Figura 1. Comportamiento del COP EN PAíses UniVERSAlistas



Figura 2. Comportamiento del COP EN PAíses dualistas

adicionalmente, se estableció un mayor valor diferencial de las variables de salud sobre las de educación, por lo cual estos tres países fueron clasificados como dualistas.

En el caso de Vietnam se encontraron tres características que lo definían como univer176 salista, tres excluyentes y una dual, pero la trayectoria de su sistema político socialista ha permitido una disminución en los índices de pobreza nacional, así como una alta cobertura y calidad en los servicios de salud. La injerencia estatal en los asuntos relacionados con la prestación de servicios sanitarios hace que sea caracterizado como universalista.

Sin embargo, debido al tránsito hacia el capitalismo en este país del sudeste asiático, se 


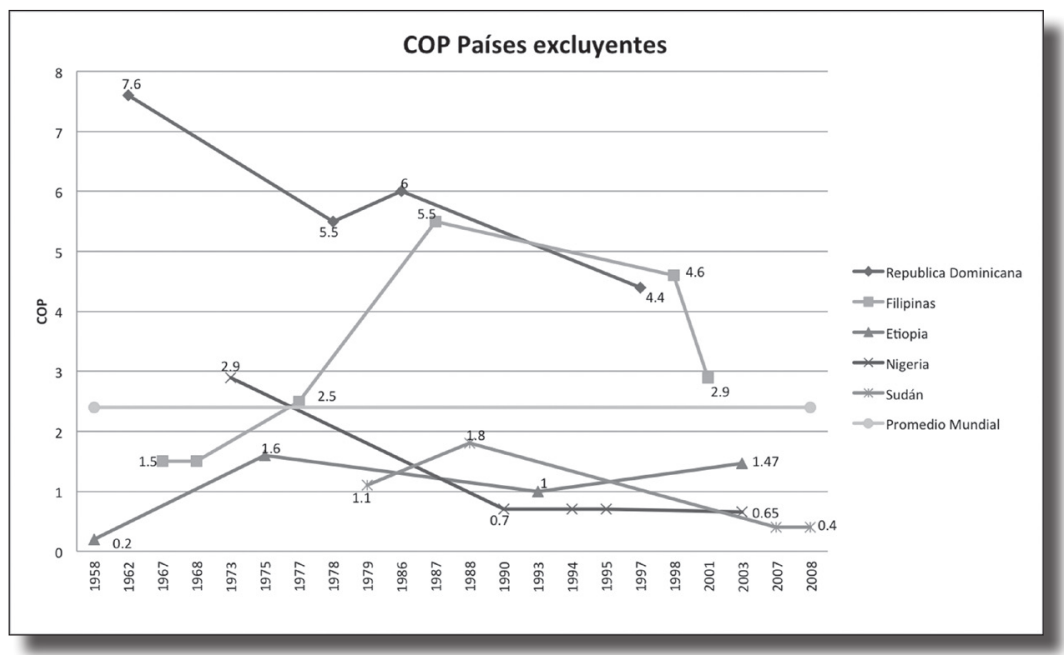

Figura 3. Comportamiento del COP En Países eXCluyentes

está permitiendo el incremento de inversión extranjera privada que propende, entre otros objetivos, por la mercantilización de los servicios ofrecidos en salud, la fragmentación sistemática de los paquetes de beneficio a los que se puede acceder y una virtual exclusión de los grupos no competitivos económicamente. Por lo anterior, no sería de extrañar que en futuras clasificaciones Vietnam quede incluido entre los países de corte dual, donde aquellos con mejor poder adquisitivo tendrán mayor y mejor acceso a dichos servicios.

Los países clasificados como universalistas en este trabajo fueron Dinamarca, Alemania, Reino Unido y Suiza, como representantes de Europa; Nueva Zelanda y Australia, por Oceanía; Vietnam por Asia; y Cuba y Estados Unidos representando a América.

Dichos países se caracterizan por poseer un sistema de salud de tipo nacional, con cobertura ampliada a toda la población. Sus sistemas, robustos, de seguridad social cuentan con una amplia red de hospitales y personal médico altamente calificado en la mayoría de los casos, con acceso a tecnologías novedosas e infraestructuras adecuadas. Los recursos necesarios para emprender dichas acciones, las más de las veces provienen de financiación estatal obtenida mediante impuestos progresivos aplicados a la población, lo que contribuye a reducir el agobio del que devenga un salario menor en comparación con los que perciben mayores entradas mensuales.

Este tipo de seguridad social está presente en países desarrollados como lo son Alemania, Dinamarca, Reino Unido, Australia, Nueva Zelanda y Suiza. A diferencia de estos países, existe un subgrupo de países universalistas cuya cobertura integral proviene de una ideología política de corte izquierdista, en contraste con el capitalismo presente en la mayoría de Estados. Dichos países, Cuba y Vietnam, han mostrado una significativa mejoría en sus indicadores de salud sin invertir tanto dinero, lo cual los coloca al lado de países con un mayor PIB nacional y gasto total en salud.

En Cuba, por ejemplo, el sistema de seguridad social se caracteriza por un financiamiento descentralizado proveniente de presupuestos municipales, es decir, una financiación totalmente estatal, la cual viene en aumento pese a la crítica situación económica, por el bloqueo económico y político de parte de los Estados Unidos. Esto muestra 
la determinación política por sostener la mejoría en diversos logros en salud y por mejorar la calidad de vida de sus ciudadanos.

Al analizar el caso particular de Estados Unidos, definido como universalista, se ve que pese a que ha logrado buenas cifras en sus indicadores de salud, en particular por ser el país con el mayor PIB per cápita del planeta, uno de los que gasta el mayor porcentaje del PIB en salud, pero también uno de los que tiene el mayor porcentaje de gasto privado. No se puede pasar por alto lo excluyente de su modelo, basado en el aseguramiento individual y una perspectiva de beneficencia para algunos sectores de la población con medicare y medicaid, donde se deja sin ningún tipo de cobertura a más de cincuenta millones de habitantes, los cuales no tienen las características para ser subsidiarios de dichos beneficios, ni los medios económicos para contratar un servicio privado.

El alto grado de cobertura presente en estos países, más allá sus particularidades, permite un mayor acceso a los servicios médicos de diferentes niveles de atención, los cuales no solo se ocupan del tratamiento una vez instaurada la enfermedad, sino que se preocupan por ahondar en la promoción de la salud y la prevención de la enfermedad, con la salvedad ya mencionada de los Estados Unidos.

Esta alta cobertura y acceso, sumados a programas de pago social mediante políticas públicas, permite la intervención por medio de medidas sanitarias como el alcantarillado y la recolección de aguas residuales, control de vectores, mejoría en las condiciones de hábitat con asentamientos seguros, recolección de basuras e inmunización temprana. Lo anterior se traduce en una notable mejoría de sus indicadores de salud, como las bajas tasas de mortalidad materno-infantil, alta

178 esperanza de vida al nacer y la disminución de incidencia de tuberculosis, entre otros.

\section{Implicaciones de la cobertura del sistema en los resultados en salud oral}

En la salud oral también se evidencia una mejoría en los indicadores que cuantifican su estatus, como el índice de sangrado gingival, el índice simplificado en higiene oral y, por supuesto, el COP, objeto de este estudio. En la literatura de los diversos países se proponen diferentes explicaciones para las tendencias a través del tiempo de este indicador, por lo que se pretende hacer un acercamiento a ellas.

En cuanto al Cop, en este estudio se observó que en las últimas décadas en la mayoría de los países industrializados ha disminuido de forma constante la experiencia de caries (ver figura 1). Esto se encuentra relacionado con lo planteado por autores como Marthaler, quién explica este fenómeno a partir de la utilización de fluoruros, la mejora de las cremas dentales, la promoción de hábitos de higiene oral, el cambio en el patrón de consumo de azúcares y carbohidratos, así como el tratamiento preventivo y los esfuerzos por lograr el éxito clínico mediante restauraciones mínimamente invasivas tipo sellantes (73).

En Vietnam, por ejemplo, desde 1991 hasta el 2001, según la Encuesta Nacional de Salud Oral, la experiencia de caries $(55,6 \%)$ disminuyó, lo cual se tradujo en una variación del índice cop de 1,8 a 1,5, comportamiento similar al evidenciado en China, donde las cifras actuales de COP corresponden a un valor de 1,0, alejándose positivamente del promedio mundial $(2,4)$; mas sin embargo, con la aclaración de que su COP en 1951 era de 0,6, y se estabiliza al alza en 1,0 en el año 2000 (74). En Vietnam, la salud oral se constituye como un bien público y suscita preocupación de los profesionales, las comunidades y el gobierno, conllevando acciones de diferente tipo como 
la educación en salud oral temprana en los niños escolares, lo cual en una mirada de más largo plazo se ha plasmado en la reducción del cop desde 2 en 1959 a 1,5 en el 2004 (46).

La educación en salud oral durante la etapa escolar de los niños vietnamitas es amplia, además, se les brinda un cuidado preventivo por parte del odontólogo. De esta manera, se crea en los niños una percepción positiva con respecto al cuidado en salud. La evidencia encontrada demuestra que antes de la intervención en promoción y prevención, el cop a los doce años de edad era de 2,0, y desde la imposición de dichas medidas en la década de los setenta, se redujo a un valor de 1,8 en los años noventa y a un 1,5 para el 2004, como ya se mencionó $(75,76)$.

Respecto de este mismo análisis, se encuentra que en Cuba la atención en salud a los niños y adolescentes (de cero a dieciocho años de edad), además de ser gratuita y obligatoria, se centra en apoyar el ciclo vital de cada individuo, es decir, desde los cero a los dos años de edad se hace énfasis en la educación a las madres con respecto a la alimentación y el control de hábitos nocivos para la salud del niño, y de los dos a los cuatro años de edad se aplican acciones de salud en promoción y prevención. En el caso de los niños mayores de cuatro años se tienen en cuenta cada una de las características de desarrollo individual (77).

Las acciones de salud en promoción, prevención, diagnóstico y tratamiento oportuno se realizan mediante un subsistema organizacional de atención estomatológica del Sistema Nacional de Salud, fundamentando la atención estomatológica desde remisión por parte del médico de familia, por lo que el sistema se presenta altamente exitoso en términos de cobertura y de calidad. Para el cuidado de la salud oral, se basa en un enfoque de manejo del riesgo, que consiste en identificar y controlar los riesgos asociados a los determinantes de la salud oral. De esta manera, la identificación de riesgos y las acciones en promoción y prevención se convierten en la principal herramienta para el mejoramiento del estado oral de los niños e individuos en general (77).

Las actividades de prevención y promoción basadas en el enfoque de riesgo se desarrollan en este país desde 1970, pero solo hasta el año 1985 se logra dar una cobertura del $100 \%$ de la población, tanto en zonas rurales como en zonas urbanas. Adicionalmente a las medidas en promoción y prevención, el diagnóstico precoz de enfermedades de salud oral, incluida la caries dental, permite evaluar y vigilar mensualmente a cada miembro de la población cubana, y semestralmente a nivel nacional, con lo cual se consiguen excelentes resultados en salud con baja inversión (77).

Estas intervenciones en materia educativa han demostrado un papel importante en la reducción significativa de valores de COP desde 1982, con un 5,1, hasta valores de 1,4 para el año 1998; sin embargo, el alto valor de cop para la década de los setenta e inicios de los ochenta no puede ser explicado solamente por la falta de intervenciones de promoción y prevención, sino también debido a la tardía implementación de planes nacionales de fluorización de agua y sal, los cuales tuvieron lugar hasta entrados los años ochenta, a diferencia de países con una alto nivel de desarrollo como los europeos que los introdujeron antes (75).

Diversos estudios muestran cómo en el oeste de Europa la prevalencia de caries llegó a ser elevada para los años anteriores a la década de los sesenta, refiriendo un promedio de COP mayor a 5 en niños de doce años de edad. Esta situación llevó a la búsqueda de medidas preventivas, reforzadas con el des- 
cubrimiento de los efectos del fluoruro en el fortalecimiento de las estructuras dentales, por lo que en la mayoría de países se implementó un número sustancial de proyectos hacia 1960. A partir de la implementación de los fluoruros en la mayoría de países europeos, como los escandinavos, se produjo una reducción significativa en los valores que miden la experiencia de caries de su población. A la par de las medidas generalizadas del uso de flúor, los países a la vanguardia en el resto de Europa evalúan el potencial preventivo de la disminución de la ingesta diaria de carbohidratos y azúcares (46,72-74).

Los primeros informes de los países escandinavos de manera agrupada fueron citados por Von Der Fehr en 1994, estos hacen mención a la disminución de la prevalencia de caries después de 1967. Ejemplo de ello es Noruega, que inició una reducción en sus índices de caries una vez introdujo programas de motivación y educación en higiene oral, como instrucción para un correcto cepillado, sumado al uso de enjuagues y cremas dentales con fluoruros. De otra parte, un informe danés, realizado por Kann en 1966, mostró un decrecimiento de la caries en más del 50\% desde 1962 hasta 1966, debido a un amplio programa escolar que comprendía la aplicación de fluoruros tópicos (46).

Estas medidas se hicieron populares en el resto de países desarrollados, llevando a que Suiza reportará una disminución de caries evidente hacia la década de los sesenta, según Kann en 1968, luego de introducir las medidas de fluorización. Muestra fehaciente del enunciado anterior es el valor reportado de COP, que fue de 10,6 para los niños de doce años de edad en 1964. Gracias a la implementación de las políticas de cuidado en salud oral se logra una reducción en 1988 mayor al $50 \%$, con un valor de 2,2, como lo muestra el Reporte Nórdico de Salud Oral, verificando una disminución sustancial en la experiencia de caries $(46,76)$.

En Alemania, el comportamiento del COP sigue bajando, ya que en 1953 se muestra que el nivel de flúor del agua potable fue uno de los determinantes en la disminución de la prevalencia de caries, como lo muestra Martheler en su estudio (73). Hacia finales de la década de los setenta reporta un valor de COP de 6,0, para finales de los ochenta un valor de 3,8 y para los noventa un valor de 1,7. Dicha tendencia se confirma con el último valor reportado incluido en este estudio, propuesto por el informe de Saheri, Hahn y Hellwig, con un valor de 0,69 en el 2008 (76,77).

En 1978 se publicó una investigación titulada El progreso en la prevención de caries, en donde Yngve y Ericsson afirman que “... en ningún otro período de la historia, a parte de aquellos tiempos de racionamiento, de guerra y hambre, estos países habían podido disfrutar de tan grande mejoría en la salud dental", debido a los métodos de prevención que se han aplicado sistemáticamente a gran escala (46).

En 1985 una comisión europea se dio a la tarea de compilar datos que demostraron disminución de caries en nueve países: Dinamarca, Finlandia, Noruega, Suecia, Australia, Países Bajos, Nueva Zelanda, Reino Unido y Estados Unidos. Los resultados fueron presentados en la "Segunda conferencia internacional de la disminución de la caries", celebrada en Londres en abril de 1994 (46).

El descenso de estos valores de COP se comportó de manera disímil entre los países que conforman Europa occidental; por ejemplo, en los Países Bajos disminuyó vertiginosamente, de 8 a 1, desde el año 1965 hasta 1993, mientras que en Suiza se observó un 
descenso más estable a lo largo de este periodo, como se muestra en la figura 1 (46).

En el Reino Unido los estudios de salud oral muestran que la experiencia de caries para 1983 tuvo un decrecimiento de $40 \%$ en el grupo de edad de los doce años. Así que la disminución del cop para 1983 permitía que los indicadores de salud oral ingleses superaran las metas propuestas por la OMS, pactadas para el año 2000, con la finalidad de conseguir, entre otros resultados, que al menos el $50 \%$ de niños a los cinco años de edad se encontraran libres de caries (46).

A mediados de los noventa, el uso dos veces al día de cremas dentales con flúor fue considerado como uno de los factores individuales más importantes para la disminución entre 20 y $40 \%$ de caries, según Marthaler. La implementación de mejores hábitos en el cepillado dental, en frecuencia y técnica, reforzando el efecto del fluoruro y el uso de sellantes, logró una disminución de más de $70 \%$ en los índices de caries (73).

La evidencia científica muestra una significativa relación entre la disminución de los niveles de cop en los países designados como universalistas y la implementación de políticas basadas en la prevención de la enfermedad y la promoción de la salud, entre las que destacan la correcta fluorización de agua o sal, así como programas de educación en higiene y autocuidado. Dichas medidas solo son posibles gracias al modelo de seguridad social implementado en estos países que, entre otras ventajas, permite el acceso universal a la educación y a la salud.

Como se había mencionado en el acápite anterior, los países catalogados como duales (México, Uruguay, Colombia, Brasil, China y Turquía) se caracterizan por tener un sistema fragmentado, patrimonialista y en algunos casos clientelista de seguridad social, que agrava la ya preocupante heterogeneidad presente en su territorio en los aspectos referentes al desarrollo económico y social, evidenciando desigualdad e iniquidad en el acceso a los servicios.

La desigualdad en el acceso a los servicios de salud, así como la calidad de estos, es evidente entre las diferentes clases económicas y sociales que conforman la población; existe una brecha entre los servicios brindados a los habitantes de las ciudades respecto a quienes viven en el campo. Las poblaciones rurales no logran superar las barreras de acceso geográfico, y menos las económicas, a la hora de consultar un servicio de salud.

Si bien en estos países se observan procesos de migración económica, de una economía rural hacia economías mixtas, bajo políticas de desarrollo nacional dirigidas a la industrialización, no todas las poblaciones están preparadas para asumir este cambio, el cual influye directamente en sus estilos de vida, sus patrones de consumo, la forma como se enferman y cómo solucionan sus problemas de salud. Este tránsito económico, caracterizado por la orientación hacia una economía basada en la exportación de las riquezas naturales y la importación de productos básicos desde las grandes potencias, ha conllevado una restructuración en el flujo de los recursos económicos, con un aumento en su PIB, aunque los beneficios esperados en materia social no alcanzan a llegar a toda la población, sino que se quedan concentrados entre los grandes empresarios que conforman la oligarquía que gobierna estas democracias en desarrollo.

Quienes integran el ápice de la pirámide económica poblacional, los grandes terratenientes, políticos, empresarios, sumados a un pequeño sector de trabajadores estatales, trabajadores de empresas multinacionales del sector energético, así como profesionales que 
devengan un altísimo salario mensual, están en capacidad de acceder a servicios privados de salud. En estos países la salud se comporta como un servicio de bienes y consumo basado en la oferta y la demanda, traduciendo el acceso a la calidad de salud como la compra y adquisición de un bien, de acuerdo con el potencial de pago, por lo que las personas que acceden al servicio prepagado de salud reciben mejores beneficios y tienen perfiles epidemiológicos que recuerdan a los países de acceso a la salud de tipo universal.

El grueso de la población debe atender sus necesidades en salud por medio de la seguridad social, sistema basado en la cotización mensual de un porcentaje del salario que devenga el trabajador para financiar su pensión y los servicios de salud que llegue a requerir, así como un aporte porcentual para aquellos que pertenecen al régimen subsidiado, dada su imposibilidad económica para cotizar. En países como Colombia, el número de empleados con contrato fijo, o por lo menos una relación laboral estable, es reducido, por lo que la relación cotizantebeneficiario se encuentra invertida. Debido a esto, la asistencia que se presta al régimen subsidiado es en la mayoría de casos precaria.

El comportamiento epidemiológico de la caries, medida en términos de COP, para México, Brasil, Uruguay y Colombia fue similar (véase figura 2), mostrando una baja constante desde inicios de la década de los noventa, sin alcanzar a posicionar dicho valor por debajo del promedio mundial, con la excepción de Colombia que para 1998 registró con 2,3 un estrecho margen inferior al promedio mundial $(2,4)$, como lo reporta el Estudio Nacional de Salud Bucal (Ensab III) (52).

En el lapso comprendido entre 1977 y 1980 , en Colombia se conocieron los beneficios de la prevención de la caries dental, así como de otras patologías, por lo que se fomentaron medidas de protección como los sellantes, aplicación de flúor y adecuados hábitos de higiene oral. Ello condujo a la creación de diferentes programas de prevención, como la acción preventiva en odontología, la fluorización del agua y sal impulsada por el Estado; también, a nivel privado, el promover la aplicación de flúor tópico y sellantes. Esto sería explicativo, en parte, para la continua reducción de los niveles de COP desde inicio de la década de los ochenta (véase figura 2).

En el caso brasileño se observaba un alto nivel de caries a finales de los setenta, con un valor reportado por la oms de 8,6 en 1976, lo que motivó la implementación de medidas de fluorización, pastas dentales con flúor, las cuales aunque lograron apenas $40 \%$ de cobertura en la población, consiguieron una reducción sustancial a un valor de COP de 4,9 en el año 1988 (46).

Esta cifra aún preocupaba al Ministerio de Salud, el cual gracias a una reforma y a la creación de un servicio público dental, el cual se encarga de promover la educación y el cuidado en la salud oral, logró cumplir el objetivo de llevar flúor al virtual $100 \%$ de su población. Pese a esto, persiste la tendencia a que en el gigante suramericano las cifras de COP superen el promedio mundial (52).

Las políticas nacionales de fluorización comenzaron a ganar popularidad entre los países latinoamericanos, incluyendo México, país que se había puesto a la vanguardia continental junto a Brasil, gracias a las milagrosas recuperaciones en sus economías. El programa de prevención de la caries dental a través de la fluorización en sal, es uno de los de mayor cobertura, este se inició desde los noventa y ha beneficiado a toda la población, con la implementación de la Norma Oficial Mexicana NOM-040-sSA1, la cual especifica la adición de yodo y flúor a la sal y su vigilancia constante (46). 
En los países asiáticos escogidos en este estudio: China y Turquía, el comportamiento reportado en el índice de experiencia de caries de su población se manifestó de manera diferente a los latinoamericanos; sin embargo, existen diferencias circunstanciales entre el comportamiento de los dos. En Turquía la presencia de caries dental en las poblaciones se relaciona directamente con los indicadores de urbanización, pues se observa cómo la mayor prevalencia de caries dental se da en regiones que se están urbanizando rápidamente. Ejemplo de ello es el aumento en el índice COP de 2,7 para el año 1987 a 3,4 en 1996. Adicionalmente, se han podido identificar otros factores relacionados con el incremento de COP, por ejemplo, que el alto consumo de azúcar tiene correlación con la aparición de caries dental; sin embargo, estos no son los únicos factores que influyen en los niveles de caries, los factores socioeconómicos también desempeñan un papel importante (78).

Como afirman Petersen et al., en países en desarrollo la prevalencia de caries aumenta con el aumento de nivel socioeconómico, mientras que en los países desarrollados disminuye al aumentar el nivel socioeconómico de los sujetos, lo que podría llevar a afirmar, erróneamente, que en los países en desarrollo se evidencia una baja prioridad del asunto de la salud oral. Diferentes estudios en países como México, Uruguay, Brasil y Colombia muestran cierta preocupación por el cuidado en salud oral, redefiniendo y creando políticas incluyentes como las mencionadas anteriormente, aunque sin alcanzar cobertura universal. Estas políticas, en el papel, parecieran poder solucionar todas las carencias en salud oral, pero debido a la imposibilidad de la cobertura total de la población, los resultados en términos de COP no han logrado alcanzar las metas propuestas $(46,74,75)$.
El caso de China es abordado al final de esta categorización para su análisis, debido al comportamiento atípico en los valores de COP con relación a los demás países tipificados como duales. Pese a que estos valores son tan bajos como los presentados en los países universalistas, es decir, están por debajo del promedio mundial, se evidencia una tendencia al alza, que aunque mínima ha sido constante, desde 1951 con 0,6 hasta el año 2000 con un valor de 1. Hay diversas explicaciones posibles para este comportamiento contradictorio, una de ellas el posible efecto de la transición política económica del comunismo hacia un capitalismo de Estado, que condiciona, entre otras cosas, una mayor mercantilización de sus servicios de salud, así como un cambio en los hábitos alimenticios, con el aumento del consumo de azúcares refinados y otros alimentos antes no disponibles para la población, generalmente cariogénicos.

Sin embargo, el valor bajo de cop en China se reporta en la literatura como resultado de una atención oral dada por el servicio público de salud oral, que pretende cubrir a toda la población y sus necesidades en atención básica primaria. Los logros conseguidos por este servicio surgen de la premisa que se ha creado en las lógicas de sus habitantes, por lo que cobra sentido la frase: "Prevenir es mejor que curar", dados los costos económicos de los tratamientos de rehabilitación oral, que tienden a ser diez veces superiores al costo de la prevención.

Los países que quedaron en el grupo de excluyentes fueron República Dominicana, Etiopía, Nigeria y Sudán, los cuales presentaban las peores cifras en los indicadores de salud escogidos. Etiopía, por ejemplo, está clasificado por el Banco Mundial como un país de desarrollo bajo, aunque recientemente está intentando optimizar los recursos destinados a la promoción y prevención, bajo 
un sistema de salud cuyo financiamiento proviene en gran parte de donaciones extranjeras por parte de instituciones como la Cruz Roja y otras ONG.

Dichas inversiones han permitido el fortalecimiento de sus establecimientos de salud, en respuesta a múltiples guerras y epidemias que han minado su proceso político y social; no obstante, dichas inversiones han sido insuficientes para atender las necesidades de la población, ya que se evidencia una carencia de personal sanitario cualificado, la cual no permite un adecuado reparto de los servicios en salud, tanto en áreas urbanas como en zonas rurales. Estas carencias condicionan el que las personas que no pueden acceder a la medicina occidental recurran a prácticas de medicina tradicional, la cual, si bien está regulada, no cuenta con un reconocimiento legal de los practicantes de dichas terapias, por lo que no se fomenta la vigilancia ni la preparación de quienes la ejercen.

La situación de Etiopía no es muy distante de la que puede identificarse en otros países de África, como Sudán y Nigeria. Se presumía al inicio del trabajo que aquellos países que quedaran clasificados en este grupo tendrían valores de COP superiores al promedio mundial $(2,4)$, valor que vendría aumentando en relación con valores reportados en décadas anteriores. El primero de los países en este grupo, República Dominicana, presentó un valor de 4,4 para el año 1997, el cual excede el promedio mundial de manera dramática. Esta cifra, mirada de manera individual, hablaría mal de su desempeño en salud oral; sin embargo, es de resaltar que para el inicio de la década de los sesenta el valor era de 7,6. De mantenerse la tendencia a la baja en este país, es de esperar que en un quinquenio

184 pueda cumplir con las metas que habían sido presupuestadas para el año 2000.
El resto de países de este grupo pertenecen al continente africano, asolado por la expoliación del capital internacional, el saqueo de sus recursos naturales, la expatriación de su talento humano, además de múltiples guerras y epidemias que han minado su capital político y social. Con este panorama se esperaba que estos países presentaran COP al alza, que superara el promedio mundial; sin embargo, de manera sorpresiva, aunque las trayectorias no se comportan de manera uniforme, ninguno supera en su última medición valores de 1,5 (véase grafica 3 ), lo cual los ubicaría a la altura de los universalistas e introduciría la pregunta de por qué, a pesar de las precarias condiciones de sus sistemas políticos sociales y de salud, los indicadores en salud oral lucen aparentemente bien.

Dentro de la literatura revisada en esta investigación, se destaca el artículo de José $\mathrm{O}$ Álvarez et al., en el que en contradicción con la hipótesis planteada inicialmente, parece resolverse esta confusión con dos afirmaciones que giran en torno al determinante nutricional como predictor del desarrollo de la caries dental.

El primero de ellos se relaciona con que los países pobres consumen per cápita la mitad o menos de azúcares refinados y carbohidratos que los países ricos, lo cual tendría un efecto protector o de disminución de caries en su población. La segunda se relaciona con la malnutrición crónica en estos países y un consecuente bajo peso y talla al nacer y durante la infancia temprana.

Diversos estudios, como los de Álvarez et al. y los de Albert Rusell et al., han verificado que la malnutrición produce menor desarrollo esquelético y demora en la erupción dental al compararla con niños con buenas condiciones nutricionales. Esto permitiría un menor tiempo de exposición de los dientes a ambientes hostiles y por ello un menor 
desarrollo de caries a la edad de los doce años, grupo de edad objeto esta revisión. Sin embargo, al pasar los años, estos niños experimentarán un mayor índice de caries en su dentición permanente, ya que la calidad de la mineralización ha sido inferior y les confiere una mayor susceptibilidad a la caries en oposición al beneficio temporal que se recibe. Lo anterior invita a afirmar que no se pueden realizar estudios de caries dental sin relacionarlos con las variables nutricionales, y que sería deseable hacer análisis de larga duración y no solamente cortes a los doce años de edad (30,78-80).

Otra posible explicación para el aumento de la experiencia en caries luego de los doce años de edad, es el contacto inadecuado que las poblaciones africanas tienen con el flúor, el cual no llega a ellas en concentraciones adecuadas, sino que es un elemento presente en las fuentes de agua naturales sin tratamiento que consumen y que se expresa a nivel sistémico con repercusión a nivel dental, como en el caso de superar 1,5 ppm, en forma de fluorosis, generando una disminución en la calidad del esmalte que le resta propiedades físicas y químicas, volviéndolo más susceptible a la acción de la caries dental. Para el resto de la población que no tiene disposición de fuentes de agua fluorada, se esperaría mayor presentación de caries por la falta del efecto protector de flúor.

Identificadas las múltiples variables (económicas, políticas, biológicas y sociales) que confluyen para la aparición de la caries dental, se vislumbran distintas posibilidades para intervenir en la prevención en torno a esta enfermedad, que sobrepasan el ámbito personal del individuo e involucran la determinación con la que los Estados abordan la temática de la cobertura en seguridad social, haciendo necesario considerar en el comportamiento estructural de cada país.
La amplia perspectiva del proceso saludenfermedad en el momento de la atención en salud oral, entendida como una red compleja de interacciones y no solamente como un factor de riesgo aislado, permite que las acciones realizadas por el profesional, en el momento de su práctica clínica, se vean afectadas por un conocimiento profundo de la sociedad, que se reflejará en los resultados en salud oral de una población. Esto incluirá el entender las limitaciones que un índice numérico como el cop presenta a la hora de ser un instrumento para la cuantificación y cualificación de las anteriores variables, por lo que es necesario implementar un nuevo gold estándar, dinámico, que pueda dialogar con la nueva corriente de la medicina social, que se denomina determinación social en salud-enfermedad.

\section{Conclusiones}

Luego de la exhaustiva revisión bibliográfica finalizada y con las limitaciones mencionadas anteriormente en el marco del desarrollo de este trabajo, nos permitimos realizar las siguientes afirmaciones y recomendaciones:

- La independencia económica de los países con respecto a entidades de carácter supranacional, permite autonomía en la formulación de políticas sanitarias que respondan a las necesidades de su población. De igual manera, aquellos que están en mora y presentan deuda externa, estarán supeditados a adaptar sus sistemas a las tendencias económicas globales, que la mayoría de veces están en contravía del fin último que le correspondería a los servicios de seguridad social: mejorar la calidad de vida de los ciudadanos.

- La determinación política de los gobiernos para brindar acceso universal 
a los servicios sanitarios de calidad a toda su población permite conseguir y mantener mejorías en los indicadores en salud, lo que contribuirá a mejorar la calidad de vida de sus ciudadanos, así como una reducción de la inequidad y un alivio a las luchas que se presentan por la diferencias marcadas entre las clases socioeconómicas.

- Los países que han implementado sistemas nacionales de salud de cobertura universal han podido llevar a cabo robustas acciones de salud en promoción, prevención, diagnóstico y tratamiento oportuno, medidas que han demostrado ser la principal herramienta para el mejoramiento del estado oral de los niños e individuos en general.

- La implementación de políticas masivas en salud oral basadas en la prevención de la enfermedad y la promoción de la salud, como la correcta fluorización del agua o de la sal, programas de educación en higiene y autocuidado, solo son posibles en los modelos de seguridad social universales, que permiten, entre otras posibilidades, el acceso universal a la educación y a la salud.

- La prevalencia de caries aumenta con el aumento de nivel socioeconómico en los países que aún no han alcanzado un sólido desarrollo económico, mientras que en los países desarrollados disminuye al aumentar el nivel socioeconómico, ya que en los primeros no se han definido correctos patrones de consumo alimenticio, como sí ocurre en los segundos.

- Una adecuada nutrición en las etapas iniciales del desarrollo óseo y dental demuestra ser un factor protector frente 186 a la caries dental, así como otras enfermedades crónicas, por lo que los pro- gramas preventivos para abordar dichas enfermedades deben acompañarse de una vigilancia nutricional que propenda por una soberanía alimentaria, basada en patrones de consumo y valores de referencia autóctonos, y no modelos abstraídos desde comunidades distales.

- $\quad$ El índice COP ha permitido, desde 1935, un acercamiento epidemiológico a las condiciones de salud oral de las poblaciones, construyendo un paradigma para la formulación de políticas en salud oral nacionales e internacionales, así como plantear metas a mediano y largo plazo, como los objetivos globales para la salud buco-dental; sin embargo, no posibilita una adecuada cualificación y cuantificación de la enfermedad, la caries dental, por lo que es necesario la implementación de un nuevo gold estándar, dinámico, que pueda dialogar con la nueva corriente de la medicina social, que se denomina determinación social de la salud-enfermedad.

- La formación integral de los profesionales de la salud, como los odontólogos, debe incluir una amplia perspectiva del contexto histórico, económico, político y social de la población en la que se centra su atención profesional, por lo que es necesario que los currículos académicos implementen una formación que trascienda el enfoque biomédico tradicional y se enfoque en la formación de individuos críticos y analíticos, cuyo quehacer profesional esté encaminado a mejorar la calidad de vida de las personas.

\section{Referencias bibliográficas}

1. Edelstein BL. The Dental Caries Pandemic and Disparities Problem. BMC Oral Health. 2006; 6 (Suppl 1): 1-5. 
2. Selwitz R, Ismail A, Pitts N. Dental Caries. The Lancet. 2007; 369 (9555): 51-9.

3. Organización de las Naciones Unidas (ONU), Departamento de Asuntos Económicos y Sociales (Desa). Objetivos de Desarrollo del Milenio; 2010.

4. Navarro V. The World Situation and the wHo. The Lancet. 2004; 363 (9417): 1321-3.

5. Abadía CE. Pobreza y desigualdades sociales: un debate obligatorio en salud oral. Acta Bioeth. 2006; 12 (1): 9-22.

6. Organización Mundial de la Salud (OMS). Informe sobre la salud en el mundo. Ginebra: oms; 2002.

7. Winslow CEA. The Untilled Field of Public Health. Modern Medicine 1920; 51 (1306): 183-91.

8. Fleury S, Molina CG. Modelos de protección social. En: Diseño y gerencia de políticas y programas sociales. Banco Interamericano de Desarrollo, Instituto Interamericano para el Desarrollo Social (Indes); 2002.

9. Filgueira F. Pasado, presente y futuro del Estado Social latinoamericano: coyunturas críticas, decisiones críticas. En: Hernández Bello A, Rico de Sotelo C, editores. Protección social en salud en América Latina y el Caribe: investigación y políticas. Bogotá: Editorial Pontificia Universidad Javeriana; 2011. pp. 69-101.

10. Esping-Andersen G, Duncan G. Por qué necesitamos un nuevo Estado benefactor. México: McGraw-Hill; 2007.

11. Koning KG. Role of Fluoride Toothpaste in a Caries-Preventive Strategy. Caries Res. 1993; 27 (Suppl 1): 23-8.

12. Helm S, Helm T. Caries among Danish Schoolchildren in Birth-Cohorts 1950-78. Community Dent Oral Epidemiol. 1990; 18 (2): 66-9.

13. Campos PM. Análisis comparados de sistemas sanitarios. En: Fernández Martínez F. Salud pública. Interamericana; 1997. pp. 819-44.

14. Giacaman RA, Araneda E, Padilla C. Association between Biofilm-Forming Isolates of Mutans. Archives of Oral Biology. 2010; 55 (8): 550-4.

15. Piovano S, Bordoní N, Doño R, et al. Estado dentario en niños, adolescentes y adultos de la Ciudad Autónoma de Buenos Aires. Revista de la Facultad de Odontología UBA. 2008; 23 (55): 34-42.

16. Campus G, Sacco G, Cagetti MG, Abati S. Changing Trend of Caries from 1989 to 2004 among 12-Year Old. BMC Public Health. 2007; 7 (28): 1-6.

17. Vered Y, Zini A, Livny A, et al. Changing Dental Caries and Periodontal Disease Patterns among a Cohort of Ethiopian Immigrants to Israel: 19992005. BMSC Public Health. 2008; 8 (345): 1-7.

18. Moreira R. Epidemiology of Dental Caries in the World. Intech Open Access Publisher; 2012.

19. Levin KA, Davies CA, Topping VA, et al. Inequalities in Dental Caries of 5-Year-Old Children in Scotland, 1993-2003. European Journal of Public Health. 2009; 19 (3): 337-42.

20. Pérez Quiñones JA, Duque J, Hidalgo I. Association of Streptococcus Mutants and Lactobacilli with Dental Caries in Children. Facultad de Ciencias Médicas de Matanzas; 2007 [Internet]. Disponible en: http://www.bvs.sld.cu/revistas/est/vol44_4 07/ est02407.htm

21. Duque J, Pérez Quiñonez A, Hidalgo I. Caries dental y ecología bucal, aspectos importantes a considerar. Facultad de Ciencias Médicas de Matanzas; 2006 [Internet]. Disponible en: http://www.bvs.sld. cu/revistas/est/vol43_1_06/est07106.htm

22. Schroth J, Smith PJ, Whalen JC, et al. Prevalence of Caries among Preschool-Aged Children in a Northern Manitoba Community. Journal of the Canadian Dental Association. 2005; 71 (1): 27-27e.

23. Petersen PE, Bourgeois D, Ogawa H, EstupinanDay S, Ndiaye C. The Global Burden of Oral Diseases and Risks to Oral Health. Bulletin of the World Health Organization. 2005; 83 (9): 661-9.

24. Granath L, Cleaton P, Fatti P, Grossman ES. Prevalence of Dental Caries in 4 to 5 Year-Old Children Partly Explained by Presence of Salivary Mutants Streptococci. Journal of Clinical Microbiology. 1993; 31(1): 66-70.

25. Consultation JWE. Diet, Nutrition and the Prevention of Chronic Diseases. Geneva: wHO; 2003.

26. Mendes FM, Braga MM, Oliveira LB, et al. Discriminant Validity of the International Caries Detection and Assessment System (Icdas) and Comparability with World Health Organization Criteria in a Cross-Sectional Study. Community Dental and Oral Epidemiology. 2010; 38: 398-407.

27. Künzel W, Fischer T. Caries Prevalence after Cessation of Water Fluoridation. La Salud, Cuba. 2000; 34 (1): 20-5.

28. Arora A, Scott J, Bhole S, et al. Early Childhood Feeding Practices and Dental Caries in Preschool Children: A Multi-Centre Birth Cohort Study. BMC Public Health. 2001; 11 (28): 1-7.

29. Alvarez J. Nutrition, Tooth Development, and Dental Caries. The American Journal of Clinical Nutrition. 1995; 61: 410s-6s.

30. Parisotto TM, Steiner-Oliveira C, Duque C. Relationship among Microbiological Composition and Presence of Dental Plaque, Sugar Exposure, Social Factors and Different Stages of Early Childhood Caries. Archives of Oral Biology. 2010; 55 (5): 365-73.

31. Watt R. Strategies and Approaches in Oral Disease Prevention and Health Promotion. Bulletin of the World Health Organization. 2005; 83 (9): 711-8.

32. Gispert A, Rivero L, Cantillo E. Relación entre el grado de infección por Estreptococos mutans y la posterior actividad cariogénica. Revista Cubana de Estomatología. 2000; 37 (3): 157-61.

33. Watt R. From Victim Blaming to Upstream Action: Tackling the Social Determinants of Oral Health Inequalities. Community Dentistry and Oral Epidemiology. 2997; 35 (1): 1-11.

34. Hobdell M, Oliveira E, Bautista R, et al. Oral Disease and Socio-Economic Status (SES). British Dental Journal. 2003; 184 (2): 91-6.

35. Sabbah W, Tsakioso G, Sheiham A, Watt R. The Role of Health Related Behaviors in the Socioeconomic Disparities in Oral Health. Social Science and Medicine. 2009; 68 (2): 298-303. 
36. Aida J, Kondo K, Kondo N, et al. Income Inequality, Social Capital an Self-Rated Health and Dental Status in Older Japanese. Social Science and Medicine. 2011; 73 (10): 1561-8.

37. Nithila A, Bourgeois D, Murtomaa H. who Global Oral Data Bank, 1986-1996: An Overview of Oral Health Surveys at 12 Years of Age. Bulletin of the World Health Organization. 1996; 76 (3): 237-44.

38. Edelstein B. The Dental Caries Pandemic and Disparities Problem. BMC Oral Health. 2006; 6 (Suppl 1): 1-5.

39. Estrada-Montoya JH. Una cuestión poco cono-sida: evaluación crítica del proyecto piloto de educación para la sexualidad y la construcción de ciudadanía. Bogotá: Universidad Nacional de Colombia; 2009.

40. León L. Sistema Internacional de Valoración y Detección de Caries Dental (Icdas). 2009.

41. World Health Organization (wHo). Icdas Application of the International Classification of Diseases to Dentistry and Stomatology. Ginebra: wHO; 1995.

42. Nishi M, Sthernswärd J, Carlsson P, Bratthall D. Caries Experience of some Countries and Areas Expressed by the Significant Caries Index. Community Dental and Oral Epidemiology. 2002; 30 (4): 296-301.

43. Sculler AA, Holst D. Oral Status Indicators DMFT and FS-T: Reflections on Index Selections. European Journal of Oral Sciences. 2001; 109 (3): 155-159.

44. Milciuviené S, Bendoraitiené E, Andruskevienciené V, et al. Dental Caries Prevalence among 12-15 Years Olds in Lithuania between 1983 and 2006. Medinica (Kaunas). 2009; 45 (1): 115-21.

45. Duque Naranjo C, Mora Díaz I. La representación de la epidemiología de la caries en el mundo a través de mapas. Universitas Odontologica. 2012; 31 (66): 41-50.

46. Petersen PE. The World Oral Health Report 2003: Continuous Improvement of Oral Health in the $21^{\text {st }}$ Century - The Approach of the wHO Global Oral Health Programme. Community Dent Oral Epidemiol. 2003; 31 (Suppl 1): 3-24.

47. Adewakun AA. Health Conditions of the Caribbean - Oral Healt. Trinidad: School of Dentistry.

48. Ivankivik A, Kresimir Lukic I, Ivankovic Z, et al. Dental Caries in Post-War Bosnia and Herzegovina. Community Dentistry and Oral Epidemiology. 2003; 31: 100-4.

49. Widström E, Eaton A, Borutta A, et al. Oral Healthcare in Transition in Eastern Europe. Brittish Dental Journal. 2001; 190 (11): 580-4.

50. Johansson V, Söderfeldt B, Axtelius B. Oral B's Nordic Report on Oral Health. Malmö: Malmö University, Faculty of Odontology, Department of Oral Public Health; 2007.

51. Petersen PE. Improvement of Oral Health in Africa in the $21^{\text {st }}$ Century - The Role of the wHo Global Oral Health Programme. African Journal of Oral Health. 2004; 1 (1): 2-16.

52. Colombia, Ministerio de Salud. Ensab III. Bogotá, 1999.

53. Organización de las Naciones Unidas. Objetivos de Desarrollo del Milenio, Informe de 2012. 2012.
54. FDI, OMS, IADR. Objetivos globales para la salud bucodental. 2003.

55. Granda E. La salud pública y las metáforas sobre la vida. Rev Fac Nac Salud Pública. 2000; 18 (2): 83-100.

56. Polanyi K. La gran transformación. Madrid: Ediciones de La Piqueta; 1997.

57. Estrada-Montoya JH. La época del imperialismo y sus implicaciones en la salud pública. Rev Fac Nac Salud Pública. 2008; 2 (26): 215-22.

58. Garvy. Kondratieff Theory of the Long Cycles. REStat. 1943; 25: 203-20.

59. Klein N. La doctrina del shock: el auge del capitalismo del desastre. Barcelona: Paidós Editores; 2007.

60. Giraldo C. El origen de la protección social. En ¿Protección o desprotección social?: Desde Abajo; 2007. pp. 39-87.

61. Regalado R. América Latina entre siglos. Dominación, crisis, lucha social y alternativas políticas de la izquierda, segunda edición. Ocean Sur; 2006.

62. García C. La medicina estatal en América Latina (1880-1930). Revista Latinoamericana de Salud. 1981; 2 (30): 70-110.

63. Fleury S. Estado sin ciudadanos. Buenos Aires: Lugar Editorial; 1997.

64. Flora P. Growth to Limits: The Western European Welfare States since World War II. Nueva York: Walter de Gruyter; 1986.

65. Esping-Andersen G. The Three Worlds of Welfare Capitalism. Princeton: Princeton University Press; 1990.

66. Esping-Andersen G. Power and Distributional Regimes. Politics and Society. 1985; 14 (2): 223-56.

67. Mesa-Lago C. Social Security in Latin America. Pressure Groups, Stratification and Inequality: University of Pittsburg; 1978.

68. Organización Internacional del Trabajo (OIT). De Bismarck a Beveridge: seguridad social para todos. Trabajo, la Revista de la ort. 2009.

69. Comisión Económica para América Latina y el Caribe (Cepal). Panorama Social de América Latina. Chile: Cepal; 1998.

70. Filgueira F. Tipos de welfare y reformas sociales en América Latina. Eficiencia, residualismo y ciudadanía estratificada. En Reforma do Estado e Mudanca institucional no Brasil. Recife: Editora Massangana; 1999. pp. 123-58.

71. Evans P. El Estado como problema y como solución. En: Camou A. Los desafíos de la gorbernabilidad. México D.F: Plaza y Valdés; 2001.

72. Organización Panamericana de la Salud (ops). Indicadores de salud: Elementos básicos para el análisis de la situación de salud. Boletín Epidemiológico. 2001; 22 (4): 1-3.

73. Marthaleer TM. Changes in Dental Caries 1953 2003. Caries Research. 2004; 38: 173-81.

74. Petersen PE, Bian JY, Zhang X. The Second National Survey of Oral Health of Children and Adults in China. International Dental Journal. 2002; 52: 283-90.

75. Petersen PE. Continuous Improvement of Oral Health in the $21^{\text {st }}$ Century - The Approach of the 
wHo Global Oral Health Programme. World Health Organization; 2003.

76. Petersen PE, Zhoug E. Dental Caries and Oral Health Behaviour Situation of Children, Mothers and Schoolteacher in Wuhan, People's Democratic Children. International Dental Journal. 1998; 48: 210-6.

77. Rodríguez Calzadilla A, Valiente Zaldivar C. Atención estomatológica en niños y adolescentes durante el año 1999 en Cuba. Revista Cubana de Estomatología 2001; 38 (3): 170-75.

78. Saheri D, Hahn P, Hellwing E. The Development of a Directed Population Approach to Tackle Inequa- lities in Dental Caries Prevalence among Secondary School Children Based on a Small Area Profile. Cent Eur J Public Helath 2008; 16 (2): 65-70.

79. Namal N, Yüceokur AA, Can G. Significant Caries Index Values and Related factors in 5-6-Year-Old Children in Istanbul, Turkey. La Revue de Santé de la Méditerranée Orientale 2009; 15 (1): 179-84. 80. Rusell A, Littetlon N, Leatherwood E, et al. Dental Surveys in Relation to Nutrition. Nutrition. 1960; 75 (8): 717-23. 